\title{
A LITERATURE REVIEW OF THE HEAD-SIZE EFFECT ON THE CAPACITY OF CAST-IN ANCHORS
}

\author{
G. DI NUNZIO ${ }^{*}$, G. MUCIACCIA ${ }^{\dagger}$ \\ * Politecnico di Milano \\ Department of Civil and Environmental Engineering, Bulding n.4 \\ Piazza Leonardo da Vinci 32, 20133 Milan, Italy \\ e-mail: giuseppe.dinunzio@polimi.it,www.dica.polimi.it \\ $\dagger$ Politecnico di Milano \\ Department of Civil and Environmental Engineering, Bulding n.3 \\ Piazza Leonardo da Vinci 32, 20133 Milan, Italy \\ e-mail: giovanni.muciaccia@polimi.it,www.dica.polimi.it
}

Key words: Cast-in anchors, Concrete cone, Head-size, Fasteners, Literature review.

\begin{abstract}
The design and the verification of anchorage to concrete are currently covered by the so called "Concrete Capacity Design" approach, which is adopted in the most recent codes and national regulations. Although it is quite advanced, such an approach is built on a wide range dataset, which encompasses both cast-in and post-installed anchors with very different geometry and tested under different boundary conditions. As a result, the CCD method was developed in a consistent way adopting the simplifying assumption that some parameters, such as the head-size, have a negligible influence on the pull-out capacity of the anchoring system. As the head-size increases, some authors found that the method could be rather conservative, while others found that the method is still accurate. Within this context, a literature review of the research studies and of the available formulas for predicting the capacity of cast-in anchors is addressed in this paper, focusing on the effect of the head-size.
\end{abstract}

\section{INTRODUCTION}

Several solutions for fastening structural and non-structural elements to concrete have been developed in the last decades. The request for more flexibility in the design and rehabilitation of civil structures focused the attention of research on the behavior of postinstalled systems. However, several applications require the use of cast-in place solutions.

The first approval for a post-installed system was released in 1975. From this point on, a lot of efforts have been dedicated to the reach a comprehensive knowledge on fastening behavior, focusing on mechanical interlock and the mechanics of expansion anchors. The research started in Germany in the mid ' 80 s and at the beginning of ' 90 s an extended version of the k-method was firstly proposed by Hilti. This version was the first application-oriented method, since it distinguished among different direction of loading. The first design method for cast-in anchors was developed in United States (US) in the mid ' $70 \mathrm{~s}$ and it was adopted by ACI Committee 349. Due to the lack of design aids for cast-in parts, this method was often used by designed also in Europe [1].

The need of design reliable steel to concrete connections drove the improvements of the existing design procedure available at the time. These improvements were finally summarized in the so-called Concrete Capacity Design 
method (CC method hereinafter), which coupled the accuracy of the k-method with the transparency of ACI 349 approach. The main improvements introduced by this approach were the distinction between different directions of loading, modes of failure and condition of the base material [1]. The abovementioned design approach is currently adopted in the most advanced design codes and national regulations, for both cast-in place and post-installed anchors.

Fasteners loaded in tension may exhibit four different failure mechanism [2]. Assuming the embedment depth not sufficient to ensure ductile steel failure and the concrete member properly designed to resist the effects induced by the fastener, concrete cone failure is the decisive failure mechanism. As it will be discussed, pull-out for cast-in anchors is mainly a fictitious failure mechanism with increasing displacements than a real failure mode.

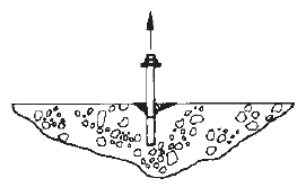

$a_{1}$ ) Pull-out

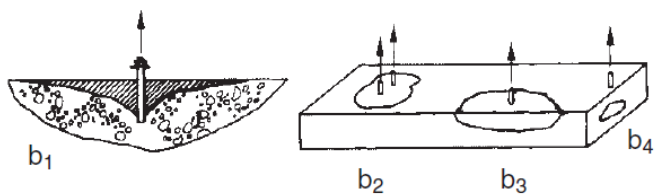

b) Concrete cone failure

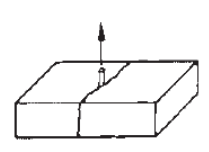

$\mathrm{C}_{1}$

c) Splitting failure

$\left.a_{2}\right)$ Pull-through

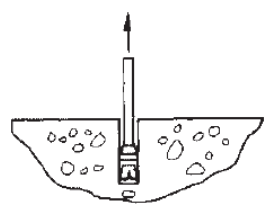

Figure 1: Failure modes associated with tensile loading [2].

Within this context, a literature review on the behavior of cast-in place anchors when concrete cone breakout is the dominant failure mechanism is presented hereinafter. Although it is quite advanced, CC approach is built on a wide range dataset, which encompasses both cast-in and post-installed anchors with very different geometry and tested under different boundary conditions. As a result, the CC method was developed in a consistent way adopting the simplifying assumption that some parameters, such as the head-size, have a negligible influence on the pull-out capacity of the anchoring system. Therefore, the design and the verification of cast-in solutions often concerns simple detailing rules and the designer's experience using anchors of various sizes under the assumption that the structural behavior is unaffected by the size of the head. From the comparison between tested and predicted failure loads, some authors found how the method could be rather conservative for large head-size anchors [3] [4]. Among them, Nilforoush [5] extensively analyzed the database of $\mathrm{CC}$ method as function of the bearing stress (Figure 2). From the analysis of the data, he concluded that CC method has not been developed in a consistent way with respect to the size of anchor heads over the range of the studied anchor embedment depths, because the bearing stresses under the heads of the tested anchors varied significantly [5]. As a matter of facts, Fuchs [1] reported that the $\mathrm{CC}$ method was developed by assembling the European and the North American test data from previous decades.

Nevertheless, as reported in some projects, cast-in anchors geometry, and particularly the head-size, could be well beyond the range of applicability of CC method [6] [7].

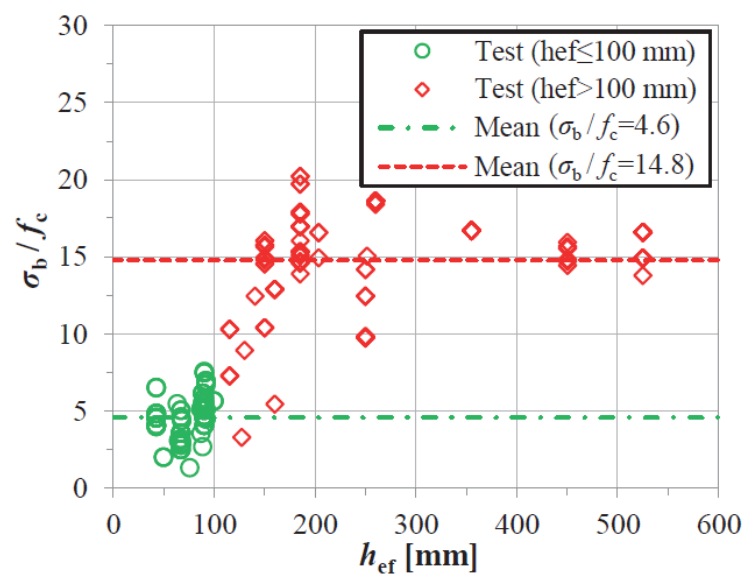

Figure 2: Ratio of the bearing stress under the heads of the tested headed anchors at peak load to the concrete compressive strength as a function of anchor embedment depth[5]. 


\section{SCOPE}

The main objective of the present paper is to review existing literature review on the available models for predicting the concrete cone capacity of cast-in place anchors, with particular emphasis on the influence of the head-size. The most relevant studies from literature are reported and discussed.

The plane of the paper is as it follows: in the section titled "National codes and regulations" the current design provisions as adopted by different codes are described; in the section titled "Research studies" the most relevant studies on anchorage behavior are reported and discussed, highlighting still open critical issues; finally, some conclusions are provided placing this work in a larger context. Sub-sections are introduced and titled as useful support for the reader.

\section{NATIONAL CODES AND REGULATIONS}

As a premise for the literature review, the most advanced codes and regulations are summarized as it follows. Some of the equations reported herinafter are, indeed, adopted in most of the research studies presented in the following section.

\subsection{ACI 349-90}

ACI 349-90 [8] provided a model based on the $45^{\circ}$ degrees concrete cone approach, as it follows:

$$
N_{u, m}=0.96 \cdot \sqrt{f_{c c}} \cdot h_{e f}^{2.0} \cdot\left(1+\frac{d_{h}}{h_{e f}}\right)
$$

Where: $N_{u, m}$ is mean concrete cone capacity in $(N)$ the $f_{c c}$ is the concrete compressive strength measured on cubes in $\left(\mathrm{N} / \mathrm{mm}^{2}\right), h_{e f}$ is the effective embedment depth in $(\mathrm{mm})$ and $\mathrm{dh}$ is the head diameter in $(\mathrm{mm})$.

\subsection{ACI 318-14}

ACI 318-14 [9] incorporated the CC method with minor modifications only. The $\mathrm{CC}$ method is based on the assumption that the size-effect for concrete cone mechanism achieves its maximum value according to the Bažant's law [10] and the failure load increases proportionally to $h_{e f}^{1.5}$. Nevertheless, from experimental tests and numerical analyses on large size anchors, it was found that the size-effect decreases [3] [4], thus the ACI 318 provides an alternative approach as it follows:

$$
\begin{gathered}
N_{u, m}=\alpha \cdot \sqrt{f_{c}} \cdot h_{e f}^{\beta} \\
\alpha=16.8, \beta=1.5 \text { for } 0<h_{e f}<280 \\
\alpha=6.535, \beta=5 / 3 \text { for } 280 \leq h_{e f} \leq 635
\end{gathered}
$$

Where: $N_{u, m}$ is mean concrete cone capacity in $(N), f_{c}$ is the concrete compressive strength measured on cylinders in $\left(\mathrm{N} / \mathrm{mm}^{2}\right)$ and $h_{e f}$ is the effective embedment depth in $(\mathrm{mm})$.

\subsection{EN 1992-4: 2018}

EN 1992-4 [11] adopts the formulas from CCD approach. Following the equations are reported with reference to mean and not to characteristic values:

$$
N_{u, m}=k_{1} \cdot \sqrt{f_{c}} \cdot h_{e f}^{1.5}
$$

$k_{1}=16.8$ for uncracked concrete

$k_{1}=11.8$ for uncracked concrete

Where: $N_{u, m}$ is mean concrete cone capacity in $(N), f_{c}$ is the concrete compressive strength measured on cylinders in $\left(\mathrm{N} / \mathrm{mm}^{2}\right)$ and $h_{e f}$ is the effective embedment depth in $(\mathrm{mm})$.

\subsection{Other design-oriented documents}

The CC approach was integrated in other design-oriented documents in Europe and, particulary, in CEB Design Guide [12], in fib bulletin 58 [13]. Since these documents adopted an unaltered version of the method, they are not adressed in detail.

\section{RESEARCH STUDIES}

In the past, literature reviews regarding the behavior of anchorage in concrete were published by different authors. In 1982, Klingner and Mendonca [14] reviewed the available procedure for predicting tensile capacity of anchor bolts and welded studs, with reference to both steel and concrete related failure modes. They performed an 
extensive comparison between the test data and the predicted capacity available till the time of the publication, providing recommendations for design and verification. Few years later, Eligehausen and Sawade wrote a contribution to the Technical Committee 90-FMA RILEM, in which they summarized the proposed analytical models by distinguish among different theoretical approaches based on theory of elasticity, theory of plasticity, strength criterion with smeared crack and fracture mechanics [15]. In the framework of the International RILEM Symposium on Connections between Steel and Concrete, Fuchs [1] presented a paper with a detailed review of the evolution of design approaches for fastening to concrete till the beginning of the $21^{\text {st }}$ century. The most recent background for the cone capacity is available in Eligehausen, Silva and Mallée [2].

The authors would like to expand the above-mentioned literature reviews by including some comments on the head-size effect, which are not provided in the original versions, and by adding the most recent research projects available.

\subsection{The $45^{\circ}$ model}

One of the first model for the prediction of concrete cone capacity was developed in the framework of the researches on nuclear-related structures by Cannon et al [16]. In this model, the cone is defined assuming a failure surface radiating from the anchor head to the surface at an assumed angle of $45^{\circ}$. The capacity is then calculated imposing the equilibrium between the external load and the projection of the nominal tensile stress acting perpendicular to the surface of the cone. The distribution of tensile stress along the side of the cone is taken linear with the maximum at the head location and zero at the concrete surface. Seeking for simplicity, an average value for the tensile stress is assumed equal to $4 \sqrt{f_{c}}$ in [US] units.

The final equation for the cone capacity is at it follows:

$$
\begin{gathered}
N_{u, m}=f_{c t} \cdot A_{N} \\
f_{c t}=4 \cdot \sqrt{f_{c}}
\end{gathered}
$$

Where: $N_{u, m}$ is mean concrete cone capacity in (lb) the $f_{c}$ is the concrete compressive strength measured on cylinders and $\mathrm{AN}$ is the projected area of the concrete cone on the member surface.

The head-size is directly included in the shape of the extraction cone. The effect of the head-size parameter is, however, to increase the projection of the arbitrary $45^{\circ}$ cone only. It was demonstrated that this method leads to unconservative predictions of the cone capacity [17] [6].

This procedure for predicting the cone capacity was adopted in several US references, as PCI Design Handbook, TRW-Nelson, TVA Civil Standard and ACI Committee 349 [14]. According to Fuchs [1], this design approach was originally adopted by ACI 349 because it was conceptually simple and in satisfactory agreement with the limited tests results available at the time. Fuchs provided also an additional explanation for the adoption of this method in ACI 349: since the ACI Committee was concerned with the nuclear-related structures, the philosophy was to design ductile fastening [17]. Sufficient embedment depth such that the concrete must exceed the strength of the steel was, indeed, suggested.

\subsection{Fracture mechanics-based description of concrete cone}

A detailed survey regarding the fracture mechanics-based description of concrete cone breakout is available in Eligehausen, Mallée and Silva [2]. Several theoretical models were developed from the mid ' 80 s till the early ' 90 s to explain concrete cone breakout. Ballarini et al. [18] developed an analytical model on the basis of experimental results. Although they focused the attention on the stability of the crack growth, they firstly investigated the effect of different head-sizes, as depicted in Figure 3 


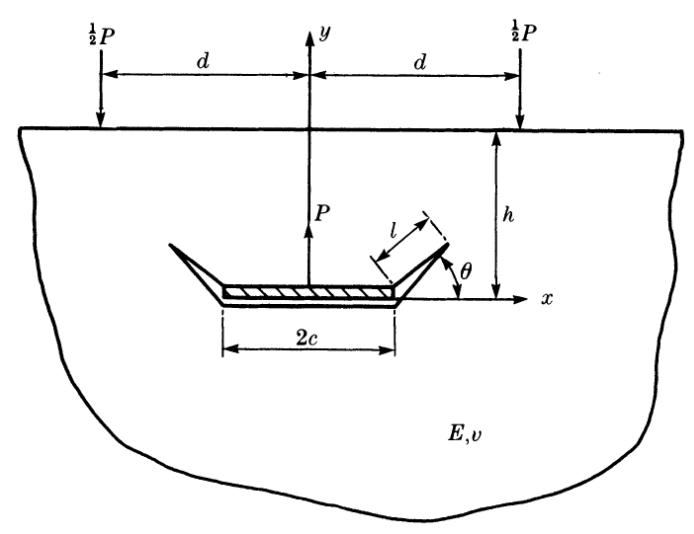

Figure 3: Mathematical model for an embedded anchor [18].

Since they systematically scaled up the ratio of head-size and supports distance with respect to the embedment depth, the results cannot be directly interpreted in terms of headsize effect. However, it was observed that the I mode stress-intensity factor tends to decrease as the head-size increases. Elfgren [19] numerically investigated concrete cone breakout assuming three different paths for the crack path: i. a straight crack inclined $45^{\circ}$ degrees with respect to the vertical direction; ii. a straight crack inclined $67^{\circ}$ with respect to the vertical direction; iii. a curved crack with an initial inclination of $73^{\circ}$. He found that the $45^{\circ}$ path is unlikely to develop in real structures, because the maximum stress is reached first in the shear direction. Conversely, for the $67^{\circ}$ crack path the maximum stress is reached first in tension.

Eligehausen and Sawade [20] analyzed the results from experimental tests on headed anchors with embedment depth from $130 \mathrm{~mm}$ to $520 \mathrm{~mm}$ and different head-sizes (Figure 4).
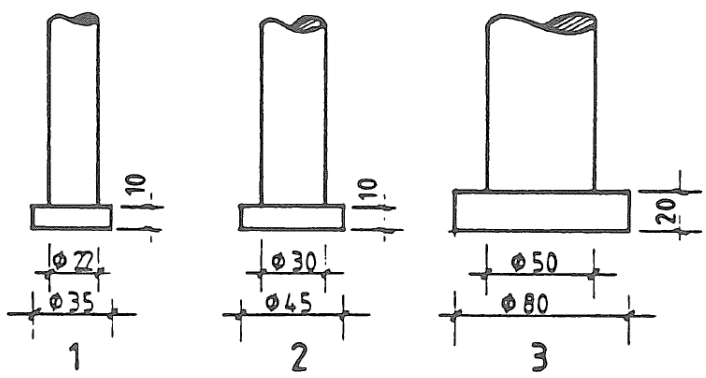

Figure 4: Different head-sizes tested by Eligehausen and Sawade [20].

Starting from an energetic model, the solution is defined by the minimization of the free energy (i.e. the sum of elastic deformation energy and surface energy along the crack). Assuming a linear fracture mechanics approach, they calculated the value of the ultimate load as it follows:

$$
\begin{gathered}
N_{u, m}=\left(E_{c} \cdot G_{f}\right)^{0.5} \cdot h_{e f}^{1.5} \cdot f\left(a / l_{B}\right) \\
\frac{a}{l_{B}}=0.45 \\
N_{u, m}=2.1 \cdot\left(E_{c} \cdot G_{f}\right)^{0.5} \cdot h_{e f}^{1.5}
\end{gathered}
$$

Where: $N_{u, m}$ is mean concrete cone capacity in $(N), E_{c}$ is the elastic modulus of concrete in $\left(\mathrm{N} / \mathrm{mm}^{2}\right), G_{f}$ is the I mode fracture energy, a the actual crack length measured along the crack path, $l_{B}$ is the assumed crack path $\left(37.5^{\circ}\right.$ with respect to the horizontal direction, $h_{e f}$ is the effective embedment depth in $(\mathrm{mm})$

Calculating the failure load from $\mathrm{CC}$ method in uncracked concrete, the bearing pressure is approximately equal to $15 \cdot f_{c}$ for all the tests, thus no conclusions can be argued on the influence of head-size. Nevertheless, it is worth to be noticed how the ratio $a / l_{B}$ was found to decrease for larger embedment depth, thus clearly indicating the presence of sizeeffect.

The size-effect on concrete was further investigate by Eligehausen et Ožbolt [21] and by Eligehausen et al. [22] during the so-called "Prague tests". In the first study, Eligehausen and Ožbolt numerically simulated the behavior of anchor bolts with three different embedment depths: $50 \mathrm{~mm}, 150 \mathrm{~mm}$ and $450 \mathrm{~mm}$. Using the Bažant's size-effect low [10], they calibrated the constants from linear regression analysis of the obtained failure loads (Figure $5)$.

$$
\begin{gathered}
N_{u, m}=k \cdot \sqrt{f_{c c}} \cdot h_{e f}^{2.0} \cdot\left(1+\frac{h_{e f}}{h_{e f}^{0}}\right)^{-0.5} \\
N_{u, m}=2.7 \cdot \sqrt{f_{c c}} \cdot h_{e f}^{2.0} \cdot\left(1+\frac{h_{e f}}{50}\right)^{-0.5}
\end{gathered}
$$

Where: $N_{u, m}$ is mean concrete cone capacity in $(N), f_{c c}$ is the concrete compressive strength measured on cubes in $\left(\mathrm{N} / \mathrm{mm}^{2}\right), h_{e f}$ is the effective embedment depth in $(\mathrm{mm}), k$ and $h_{e f}^{0}$ are the calibration factors according to the Bažant's law. 


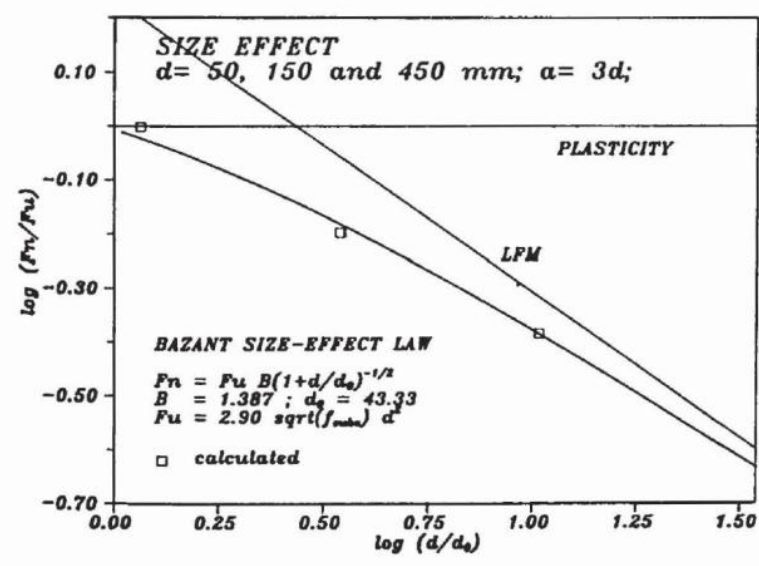

Figure 5: Comparison between size-effect law and numerical results from Eligehausen et al [21].

On the "Prague tests", the size-effect of concrete cone was experimentally investigated using the same embedment depths of the previous stud but performing two series of tests: the former, identified with "A", assuming an head diameter 1.90 times the shaft diameter and the latter, identified with "B", for which the head diameter was fixed such to obtain a constant head pressure equal to $14 \cdot f_{c}$. The size-effect law was, then, recalibrated according to the test results as it follows:

$$
N_{u, m}=10 \cdot f_{c c}^{0.5} \cdot h_{e f}^{1.6}
$$

Where: $N_{u, m}$ is mean concrete cone capacity in $(N), f_{c c}$ is the concrete compressive strength measured on cubes in $\left(\mathrm{N} / \mathrm{mm}^{2}\right), h_{e f}$ is the effective embedment depth in $(\mathrm{mm})$.

From the comparison between test results, it was observed an increase of the failure load for larger heads (test series A). Such an increase of the failure load could be hidden in the exponent of equation (7), which slightly differs from equation (6) (i.e. assumed maximum size-effect).

\subsection{The Concrete Capacity approach}

The genesis of the $\mathrm{CC}$ approach (or CCD in US) for fastening to concrete, as published on ACI Structural Journal and later adopted by the most recent design codes, was explained in detail by Fuchs [1], who is also one of the author of the method. The method was developed by implementing the expanded kfactor method by a user-friendly rectangular prism model, as depicted in Figure 6. The critical edge distance for headed
studs, headed bolts, expansion anchors, and undercut anchors is $1.5 \mathrm{~h}_{\mathrm{ef}}$.
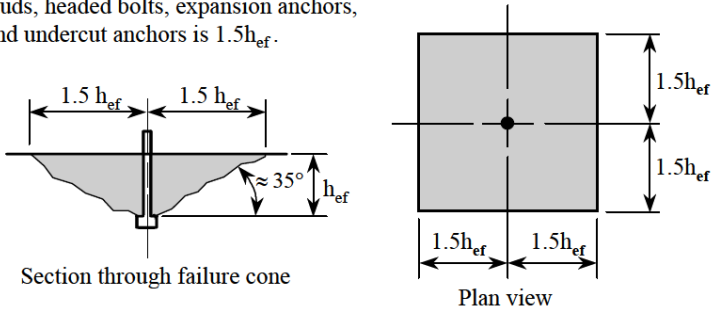

$$
\begin{aligned}
\mathrm{A}_{\mathrm{No}} & =2 * 1.5 \mathrm{~h}_{\mathrm{ef}} \times 2 * 1.5 \mathrm{~h}_{\mathrm{ef}} \\
& =3 \mathrm{~h}_{\mathrm{ef}} \times 3 \mathrm{~h}_{\mathrm{ef}} \\
& =9 \mathrm{~h}_{\mathrm{ef}}^{2}
\end{aligned}
$$

Figure 6: Concrete cone surface idealized according to CCD approach.

The main difference with the approaches from the " 70 s relies on the fracture mechanics approach. The main outcome from the models of late ' $80 \mathrm{~s}$ till the middle ' $90 \mathrm{~s}$ it that the concrete cone breakout is affected by the sizeeffect. The failure loads, thus, increases less the available failure surface, and is given by the following equation:

$$
\begin{gathered}
N_{u, m}=k_{1} \cdot \sqrt{f_{c}} \cdot k_{2} \cdot h_{e f}^{2.0} \cdot k_{3} \cdot h_{e f}^{-0.5} \\
N_{u, m}=k \cdot \sqrt{f_{c}} \cdot h_{e f}^{1.5} \\
k=k_{1} \cdot k_{2} \cdot k_{3}
\end{gathered}
$$

Where: $N_{u, m}$ is mean concrete cone capacity in $(N), f_{c}$ is the concrete compressive strength measured on cylinders in $\left(\mathrm{N} / \mathrm{mm}^{2}\right), h_{e f}$ is the effective embedment depth in $(\mathrm{mm}), k_{1}, k_{2}$ and $k_{3}$ are calibration factors which can be resumed in the single $k$ factor, $k$ factor is equal to 16.8 and to 12.5 for uncracked and for cracked conditions, respectively.

From the analysis of equation (8), three different parts can be highlighted:

- $k_{1} \cdot \sqrt{f_{c}}$ which represents the nominal tensile strength of concrete;

- $k_{2} \cdot h_{e f}^{2.0}$ which represents the basis of the rectangular prism model;

- $k_{3} \cdot h_{e f}^{-0.5}$ which represents the maximum size effect according to Bažant's law.

The CC approach seems to be in contrast with the fracture mechanics description of the concrete cone failure, because no dependency of the failure load from the fracture properties is introduced. However, such a dependency is 
hidden in the $\sqrt{f_{c}}$ term. In fact, assuming that the elastic modulus of concrete is proportional to $f_{c}^{0.3}$ and the fracture energy is proportional to $f_{c}^{0.7}$, it can be easily demonstrated that $f_{c}$ is proportional to the product $E_{c} \cdot G_{f}$. Despite it is less representative of the concrete matrix fracture properties, the use of concrete compressive strength was intended for ease of utilization.

It worth to be noticed how the method does not take into account for different head-sizes.

\subsection{Behavior of small head anchors}

Lieberum investigated the compressive punching of concrete by varying the size of circular and annular bearing areas [23]. He found that the bearing pressure-displacement relation is linear till $5 \cdot f_{c}$ and $2.5 \cdot f_{c}$ for circular and annular bearings, respectively. Although they are not directly related to anchorages, the results could provide useful information about the behavior of cast-in anchors. The structural response under tensile loads is, indeed, strongly affected by the bearing pressure both in terms of stiffness and load capacity. As the pressure increases at the anchor's head location (i.e. small bearing heads), the displacements tend to increase more than linearly thus yielding a reduction of the effective embedment depth and, consequently, of the load capacity.

The behavior of headed studs subjected to tensile load was extensively investigated by Furche [24]. He described the pull-out failure as function the bearing pressure. Specifically, if the bearing area is large enough, the concrete cone resistance is not affected by the local crushing of concrete. Conversely, smaller head leads to a reduction of the effective embedment depth as consequence of concrete crushing under the head, (Figure 6).

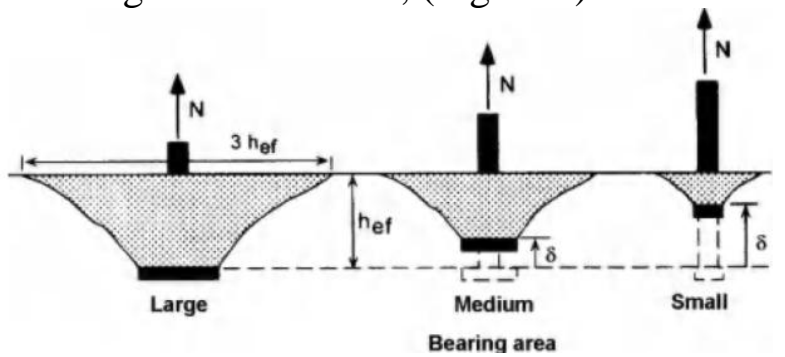

Figure 7: Schematic concrete cone breakout for different head-sizes [2].

The influence of the head-size was experimentally investigated by fixing the embedment depth at $80 \mathrm{~mm}$ and by varying the shoulder size from $0.5 \mathrm{~mm}$ to $4 \mathrm{~mm}$ (i.e. the distance measured from the shaft surface to the tip of the head). The tests were performed in both cracked and uncracked concrete. On this basis, Furche proposed the following model:

$$
\begin{gathered}
N_{u, m}=\alpha \cdot f_{c c}^{0.5} \cdot\left(h_{e f}-\delta_{u}\right)^{1.5} \\
\delta_{u}=\frac{k_{a} \cdot k_{A}}{c_{1}} \cdot\left(\frac{b_{p}}{f_{c c}}\right)^{2} \\
k_{a}=\sqrt{5 / a} \geq 1 \\
k_{A}=\sqrt{d^{2}+m \cdot\left(d_{h}^{2}-d^{2}\right)}-0.5 \cdot d_{h} \\
a=0.5\left(d_{h}+d\right) \\
b_{p}=\begin{array}{c}
N_{u, m} / A_{h} \\
m=9
\end{array} \\
c_{1}=\left\{\begin{array}{c}
600 \text { uncracked concrete } \\
300 \quad \text { cracked concrete }
\end{array}\right.
\end{gathered}
$$

Where: $N_{u, m}$ is mean concrete cone capacity in $(N), f_{c c}$ is the concrete compressive strength measured on cubes in $\left(N / \mathrm{mm}^{2}\right), h_{e f}$ is the effective embedment depth in $(\mathrm{mm}), \delta_{u}$ is the displacement at peak due to concrete crushing in $(\mathrm{mm}), a$ is the width of the sholder, $k_{a}$ and $k_{A}$ are factors function of the geometry, $b_{p}$ is the bearing pressure in $\left(\mathrm{N} / \mathrm{mm}^{2}\right)$ as function of the applied tensile load, $A_{h}$ is the head area in $\left(m m^{2}\right), d$ is the shaft diameter in $(\mathrm{mm}), d_{h}$ is the head diameter in $(\mathrm{mm})$.

As the bearing pressure increases, it was observed a reduction of the resistance about the $77 \%$ with respect to the CC method. Furthermore, limits for the bearing pressure to avoid pull-out failure without development of the cone surface were derived (Figure 8):

$$
b_{p} \leq\left\{\begin{array}{c}
20 \cdot f_{c c} \quad \text { cracked concrete } \\
30 \cdot f_{c c} \text { uncracked concrete }
\end{array}\right.
$$




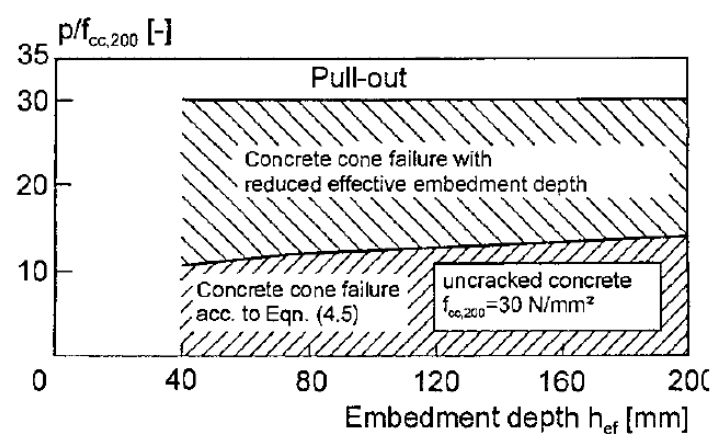

Figure 8: Maximum bearing pressure to ensure concrete cone failure without reduction of the embedment depth in uncracked concrete [2].

Berger [25] investigated the relation between load and displacement and the dimensioning of anchor bolts subjected to tensile load, with and without additional reinforcement.

$\mathrm{He}$ suggested that the displacement behavior of a bolt far from free edges and sufficiently spaced from other anchors is composed by the following contributions:

- Axial deformation of the steel shaft;

- Displacement due to concrete crushing;

- Uplift of the breakout cone.

He presented, then, a simplified model for the descending part of the load-displacement curve. Specifically, it was assumed that the contribution of the concrete cone breakout is negligible till the peak load is achieved, while the contribution of concrete crushing is fully exploided. After the peak, this contribution increases almost linearly till the fracture surface reaches the surface and load drops to zero. The slope of the descending branch is affected by the embedment depth and the compressive strength of concrete. In general, brittleness of the curve tends to increase with the compressive strength and the embedment depth. This behavior agrees with some numerical results from literature [3]. The axial deformation of the anchor shaft is calculated and summed up according to the actual value of the applied load.

From the analysis of load-displacement curves, he presented a modification for the approach originally developed by Furche, but assuming a different dependency on the concrete compressive strength as depicted in Figure 9:

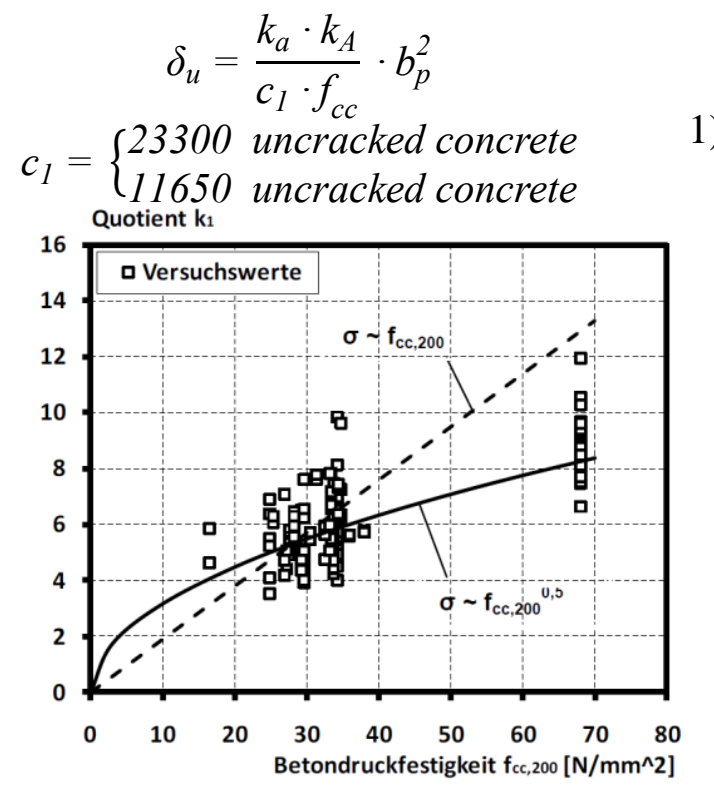

Figure 9: Influence of compressive stength on the head displacement [25].

\subsection{Behavior of large size anchors}

Ožbolt et al performed an extensive numerical investigation on anchor bolts with large embedment depths [3]. The embedment depth was varied from $150 \mathrm{~mm}$ to $1500 \mathrm{~mm}$ and, for each embedment depth, three different head-size were simulated, namely "small", "medium" and "large" head-sizes. Non-linear analyses were carried out by pulling out headed anchors from unreinforced concrete blocks. Concrete was modelled adopting the micro-plane model proposed by Ožbolt [26].

A general increasing of the resistance and of the stiffness was observed as the head-size increases. Regarding the crack patterns, it was observed that the crack length at the peak was shorter for smaller anchor heads and the cone was steeper than in the case of larger heads. Stress gradients in the neighborhood of the anchor's head is believed to be the main responsible for those differences. The size effect on concrete is smaller for larger heads, and relevant changes in the main crack is observed, which propagates in almost mode-I failure instead of mixed-mode fracture. Therefore, a refinement for the CCD approach was proposed to take into account for the effect of the head-size: 


$$
\begin{gathered}
N_{u, m}=15.5 \cdot \gamma^{k} \cdot \sqrt{f_{c c}} \cdot h_{e f}^{1.5} \\
\gamma=\frac{A_{h}}{A_{0}} \\
A_{0}=\frac{N_{u, C C D}}{20 \cdot f_{c}}=\frac{15.5 \cdot \sqrt{f_{c c}} \cdot h_{e f}^{1.5}}{20 \cdot f_{c}} \\
k=\frac{\sqrt{h_{e f}}}{100}
\end{gathered}
$$

Where: $N_{u, m}$ is mean concrete cone capacity in $(N), f_{c}$ is the concrete compressive strength measured on cylinders in $\left(\mathrm{N} / \mathrm{mm}^{2}\right), f_{c c}$ is the concrete compressive strength measured on cubes in $\left(\mathrm{N} / \mathrm{mm}^{2}\right) \quad h_{e f}$ is the effective embedment depth in $(\mathrm{mm}), N_{u, C C D}$ is the mean concrete cone capacity calculated according to CCD approach in $(N), \gamma$ is a factor that takes into account for the effective bearing area and it is equal to the ratio of the current bearing area $A_{h}$ and the area $A_{0}$ which provides the capacity from CCD approach, $k$ is an exponent that accounts for the effect of increasing embedment depth.

Although the simulation of several cases, the authors would highlight that the anchors as simulated in this research projects are still characterized by bearing pressures higher than $5 \cdot f_{c}$.

Lee et al. [6] carried out an experimental campaign on large anchors with embedment depths systematically greater than $635 \mathrm{~mm}$. Such a research project is quite rare in the technical literature because large anchors require high economical efforts to properly built and test the concrete specimens. As it will be discussed in the next section, $635 \mathrm{~mm}$ embedment depth represents the upper bound for the use of CCD approach according to US regulations.

Specimens were designed such that the embedment depth increases with constant bearing pressure, which was fixed approximately equal to $4 \cdot f_{c}$. Such a value is within the range of full cone development as suggested by other authors [2]. Although the specimens were designed to avoid splitting failure, the observed crack pattern was composed by one major crack centered on the sides of the blocks, horizontal and transversal cracks and a circular pattern around the anchor. According to Lee et al., the top and the bottom of the specimens were slightly reinforced to minimize shrinkage cracks. In authors opinion, however, this reinforcement played non negligible role on the development of concrete cone. As reported in very recent research project [7], a global mode of failure involving the entire concrete slab was observed for very low bearing pressure Therefore, it is challenging to distinguish among the cracked and uncracked conditions, since the reinforcement takes the bending/splitting cracks that cannot be avoided.

A comparison of test results with the most used predictors from technical literature was reported in the paper. From the comparison it arises that the method from ACI 349 (i.e. $45^{\circ}$ degrees model) is unconservative even for larger anchors. On the other end, CC approach is conservative for large anchors yielding to measured failure loads approximately $10 \%$ higher than the previsions. As an explanation for such an increase, it is argued that the CC method is based on linear fracture mechanics, which is valid for the smaller head-size anchors (i.e. high stress gradients in the neighborhoods of the head). Finally, it is suggested to adopt the modified CC approach according to ACI 318 Appendix D when the bearing pressure is lower to 3 or 2.4 times the concrete compressive strength in uncracked concrete and cracked concrete, respectively.

In order to investigate the influence of different parameters on the concrete cone capacity for cast-in anchors, Nilforoush recently carried out experimental tests [4] and numerical analyses [27].

From the comparison with available models, he found that the current design methods underestimate the tensile resistance of the anchors and, particularly, when the headsize increases. However, a more brittle response and increasing of the critical spacing and critical edge distance is observed. Those results match with the observations by Ožbolt [3]

Hence, a modified $\mathrm{CC}$ method was proposed for the evaluation of the expected 
cone resistance. In particular, three different coefficients, which multiplies the basic cone resistance, were calibrated on the data from numerical analyses and experimental tests. The coefficients account for the increasing of the thickness of the concrete member $\left(\psi_{H}\right)$, for the increasing of the head-size $\left(\psi_{A H}\right)$ and for the presence of surface reinforcement $\left(\psi_{S r}\right)$.

$$
\begin{gathered}
N_{u, m}=N_{u, m}^{\text {code }} \cdot \psi_{H} \cdot \psi_{A H} \cdot \psi_{S r} \\
N_{u, m}^{0}=16.8 \cdot \sqrt{f_{c}} \cdot h_{e f}^{1.5} \\
\psi_{H}=\left(\frac{H}{2.0 \cdot h_{e f}}\right)^{0.25} \leq 1.20 \\
\psi_{A H}=\left(\frac{A_{h}}{A_{0}}\right)^{0.1} \\
\begin{array}{c}
1.35\left(\frac{h_{e f}}{H}\right) \leq 1.20 H \leq 3.0 h_{e f} \\
1.00 \quad H>3.0 h_{e f}
\end{array} \\
A_{0}=\frac{N_{u, m}^{c o d e}}{15 \cdot f_{c}}
\end{gathered}
$$

Where: $N_{u, m}$ is mean concrete cone capacity in $(N), N_{u, m}^{c o d e}$ is the mean concrete cone capacity calculated according to the reference code in $(N), f_{c}$ is the concrete compressive strength measured on cylinders in $\left(\mathrm{N} / \mathrm{mm}^{2}\right), h_{e f}$ is the effective embedment depth in $(\mathrm{mm}), A_{h}$ and the area $A_{0}$ which provides the capacity from $\mathrm{CC}$ approach, $H$ is the thickness of concrete member in $(\mathrm{mm})$.

Although the method is refined, the applicability of the correction factor for CC merely taking into account the head-size can be questioned. The above-mentioned conclusion was derived in the framework of a recent research projects, in which the authors investigated the head-size effect on the behavior of cast-in anchors for real industrial applications [7]. In particular, anchor bolts with very different head-sizes were tested under monotonic tensile loading by keeping fixed the embedment depth. Calculating the ratio between predicted load and load bearing area, it follows that the second and the third investigated solutions are able to develop very low bearing pressure at the peak. Specifically, the second solution develops up to $1.7 \cdot f_{c}$, while for the very large head size the bearing pressure dramatically drops under the unity. Although these anchor bolts are representative of real applications, no comparable data are available in technical literature. A limited increase in the failure load for the very large head-size only is reported [7]. However, depending on the bearing pressure ratio, a migration from local mode of failure (i.e. pure concrete cone) to global failure involving the entire concrete slab was observed, for which surface reinforcement have been placed on purpose.

\section{CONCLUSIONS}

A literature review of the existing approaches for the prediction of the concrete cone resistance of cast-in anchors is presented in this paper, with emphasis on the effect of head-size.

Starting from the existing codes and regulations, a review of the main research studies on concrete cone capacity is reported. The background documents behind the socalled CC approach are carefully analyzed highlighting, if available, information about the influence of head-size. Two sections are, finally, dedicated to the behavior under extreme pressure conditions: small head anchors as well as large head anchors.

The following conclusions can be drawn:

- The approach adopted by the most advanced codes and regulations is the CC (or CCD) approach. Such a method provides accurate predictions for a rather wide range of cast-in anchors. However, it was found to be conservative for large head-size anchors and unconservative for small head-size anchors. This may be related to the base reference dataset, which encompass a wide range of anchors with different geometries and tests with different boundary conditions;

- Models based on fracture mechanics rarely assume the influence of head-size as relevant parameter for the behavior of cast-in anchors. This is probably due 
to the main interest in solving the sizeeffect most related to the embedment depth, which drove the research in the ' $80 \mathrm{~s}$. Since the gradient in the neighborhoods of the head strongly depends on the shape of the head, the authors suggest that the size-effect could hide a superimposition of several geometrical parameters, namely the embedment depth and the anchor's head;

- Some refinement proposals for the CC approach have been proposed for the inclusion of the head-size of cast-in anchors. For small head-size, iterative procedures were presented in order to calculate the reduction of the failure load due to concrete crushing. Conversely, for large head-size anchors, the refinement proposals were mainly based on the calibration of correction factors for the basic resistance calculated according to $\mathrm{CC}$ method. It is discussed how the applicability of refinement methods based on the introduction of correction factors can be challenged, because the fracture process of large head size anchors is found to be very different from the basic assumption of the method;

- From the results of a recent research project on anchors with very large heads, a strong interaction with the structural behavior of concrete members was found, despite the design of specimen should have ensured undisturbed conditions. On this basis, it is suggested to further investigate the influence of head-size jointly with the structural response of the concrete member.

\section{REFERENCES}

[1] W. Fuchs, "Evolution of fastening design methods in Europe," in

International Symposium on connections between steel and concrete, 2001, pp. 45-60.

[2] R. Eligehausen, R. Mallèe, and J. Silva,
Anchorage In Concrete Construction. Berlin: Ernst \& Sohn, 2006.

[3] J. Ožbolt, R. Eligehausen, G. Periškić, and U. Mayer, "3D FE analysis of anchor bolts with large embedment depths," Eng. Fract. Mech., vol. 74, no. 1-2, pp. 168-178, 2007.

[4] R. Nilforoush, M. Nilsson, and L. Elfgren, "Experimental evaluation of tensile behaviour of single cast-in-place anchor bolts in plain and steel fibrereinforced normal- and high-strength concrete," Eng. Struct., vol. 147, pp. 195-206, Sep. 2017.

[5] R. Nilforoush, "Anchorage in Concrete Strucutres - Numerical and experimental Evaluation of LoadCarrying capacity of CI headed anchors and PI adhesive anchors," Luleå University of Technology, 2017.

[6] N. H. Lee, K. S. Kim, C. J. Bang, and K. R. Park, "Tensile-headed anchors with large diameter and deep embedment in concrete," ACI Struct. J., vol. 104, no. 4, pp. 479-486, 2007.

[7] G. Di Nunzio, A. Marchisella, and G. Muciaccia, "The effect of very low bearing pressure on the behavior of cast-in anchors," in Proceedings of CONSEC 2019, 2019, pp. 1-10.

[8] ACI, ACI 349-90 - Code requirements for nuclear safety related concrete structures. 1990.

[9] ACI Committee 318, Aci 318-14. 2014.

[10] Z. P. Bažant, "Size Effect in Blunt Fracture: Concrete, Rock, Metal," $J$. Eng. Mech., vol. 110, no. 4, pp. 518535, 1984.

[11] CEN/TC250, "EN1992-4 - Eurocode 2: Design of concrete structures - Part 4: Design of fastenings for use in concrete," 2018.

[12] CEB-FIP, Fastenings to Concrete and Masonry Structures - State of Art report. Thomas Telford Services Ltd., 1994.

[13] fib, fib bulletin 58 - Design of anchorages in concrete, no. July. 2011.

[14] R. E. Klingner and J. A. Mendonca, "Tensile Capacity of Short Anchor 
Bolts and Welded Studs: A Literature Review," ACI J., vol. 79, no. 27, 1982.

[15] R. Eligehausen and G. Sawade, "Analysis of anchorage behaviour," in Fracture Mechanics of Concrete Structures: From theory to applications, L. Elfgren, Ed. London: Chapman and Hall Ltd, 1989, pp. 263-280.

[16] R. W. Cannon, E. G. Burdette, and R. R. Funk, "Anchorage to Concrete, Report No. CEB 75-32," 1975.

[17] W. Fuchs, R. Eligehausen, and J. E. Breen, "Concrete Capacity Design (CCD) Approach for Fastening to Concrete," ACI Struct. J., vol. 92, no. 1, p. 23, 1995.

[18] R. Ballarini, S. P. Shah, and L. M. Keer, "Failure Characteristics of Short Anchor Bolts Embedded in a Brittle Material," in Proceedings of the Royal Society of London. Series A, Mathematical and Physical, 1986, vol. 404, no. 1826, pp. 35-54.

[19] L. Elfgren, U. Ohlsson, and K. Gylltoft, "Anchor Bolts Analysed with Fracture Mechanics," in Fracture of Concrete and Rock, New York, NY: Springer New York, 1989, pp. 269-275.

[20] R. Eligehausen and G. Sawade, “A fracture mechanics based description of the pull-out behavior of headed studs embedded in concrete," Fract. Mech. Concr. Struct., no. July, pp. 281-299, 1989.

[21] R. Eligehausen and J. Ozbolt, "Size effect in anchorage behavior," Fract. Behav. Des. Mater. Struct., no. June, 1990.

[22] R. Eligehausen, P. Bouska, V. Cervenka, and R. Pukl, "Size effect of the concrete cone failure load of anchor bolts," First Int. Conf. Fract. Mech. Concr. Struct., no. January, pp. 517525, 1992.

[23] K.-H. Lieberum, H.-W. Reinhardt, and H. Weigler, "Das Tragverhalten von Beton bei extremer Teilflächenbelastung.," Beton- und Stahlbetonbau, vol. 84, no. 1, pp. 1-5, Jan. 1989.
[24] J. Furche, "Zum Trag- und Verschiebungsverhalten von Kopfbolzen bei zentrischem Zug," University of Stuttgart, 1994.

[25] W. Berger, "Trag- und Verschiebungsverhalten sowie Bemessung von Kopfbolzenverankerungen mit und ohne Rückhängebewehrung unter Zuglast," University of Stuttgart, 2014.

[26] J. Ozbolt, Y. J. Li, and I. Kozar, "Microplane Model for Concrete with Relaxed Kinematic Constraint," Fract. Mech. Concr. Struct., vol. 38, pp. 609616, 2001.

[27] R. Nilforoush, M. Nilsson, L. Elfgren, J. Ožbolt, J. Hofmann, and R. Eligehausen, "Tensile capacity of anchor bolts in uncracked concrete: Influence of member thickness and anchor's head size," ACI Struct. J., vol. 114, no. 6, pp. 1519-1530, 2017. 